\title{
Yabancılara Türkçe Öğretiminde Geleneksel ve Teknoloji Temelli Yaklaşımların Değerlendirilmesi
}

\author{
Emre Çalışkan ${ }^{1 *}$ \\ 1* Alanya Alaaddin Keykubat Üniversitesi, Lisansüstü Eğitim Enstitüsü, Türkçe Eğitimi Anabilim Dalı, Antalya, Türkiye, (ORCID: 0000-0002-6665-7510), \\ emrelt@gmail.com
}

(Illk Geliş Tarihi 19 Haziran 2021 ve Kabul Tarihi 13 Kasım 2021)

(DOI: 10.31590/ejosat.954701)

ATIF/REFERENCE: Çalı̧skan, E. (2021). Yabancılara Türkçe Öğretiminde Geleneksel ve Teknoloji Temelli Yaklaşımların Değerlendirilmesi. Avrupa Bilim ve Teknoloji Dergisi, (27), 921-924.

$\ddot{O} \mathbf{z}$

Küresel dinamiklerin etkisi ile insanların iş, eğitim, sağlık ve gezi gibi çeşitli amaçlarla başka ülkelere seyahat etmeleri her geçen gün artmaktadır. Şüphesiz insanların ziyaret ettikleri veya yaşadıkları diğer ülkelerde yaşadıkları en büyük zorluk dil konusunda olmaktadır. Yaşanan ülkenin kültürünü tanımak ve sağlıklı iletişim kurmak için dil öğrenimini bir gerekliliktir. Bu gereklilikten dolayı dil öğrenimine olan talep her geçen artmakta ve gerek bireyler gerekse devletler dil öğrenimi ve öğretimine önemli yatırımlar yapmaktadırlar. Eğitim başta olmak üzere, sağlık, turizm ve iş olanaklarının yüksek olmasından dolayı yabancılar tarafından yoğun şekilde tercih edilen Türkiye de şüphesiz dil öğrenimi anlamında önemli yatırımların yapıldığı ülkelerden biridir. Çeşitli sebeplerle Türkiye'ye gelen yabancılar, yaşayacakları ülkenin dilini öğrenmek için üniversitelerden, kurslardan ve teknolojik imkanlardan yararlanmaktadırlar. Bu çalışmada Türkçe Öğretim Merkezi (TÖMER) aracılığı ile Türkçe öğrenen yabancılarla görüşülmüsştür. Çalışma TÖMER özelinde yabancılara Türkçe öğretiminde geleneksel ve teknoloji temelli yaklaşımların karşılaştırmalı değerlendirilmesi yapılmıştır.

\section{The Evaluation of Traditional and Technology-Based Approaches in Teaching Turkish to Foreigners}

\begin{abstract}
With the influence of global dynamics, people's travel to other countries for various purposes such as business, education, health, and travel is increasing day by day. The biggest challenge people face in other countries they visit or live in is in language. Language learning is a necessity to get to know the culture of the country and to communicate healthily. Due to this requirement, the demand for language learning is increasing day by day, and both individuals and governments are making significant investments in language learning and teaching. Republic of Turkey where is heavily preferred by foreigners due to its high health, tourism, and business opportunities, especially education, is one of the countries where significant investments are made in terms of language learning. Foreigners who come to Turkey for various reasons go to universities, courses and get the help of technological facilities to learn the language of their country of life. In this study, a semi-structured interview technique was applied to foreigners learning Turkish through Alanya Alaaddin KeykubatUniversity (ALKU) Turkish Teaching Center (TÖMER). The study was carried out in order to evaluate comparatively whether foreign students studying at ALKU TÖMER found traditional language learning methods or technology-based approaches more useful when learning Turkish as a foreign language.
\end{abstract}

Keywords: Turkish, Technology, Language, Teaching

*Sorumlu Yazar: emrelt@gmail.com 


\section{Giriş}

İnsanlar, gelişen dünya ile yeni iş firsatlarını değerlendirmek, iyi eğitimler almak, sağlık imkanlarından faydalanmak ve yeni kültürler tanımak için başka ülkelere seyahat etmekte ve kendi ülkeleri dışında yaşamayı tercih etmektedirler. Yabancı bir ülkeye adapta olabilmek için de o ülkenin kültürü, coğrafyası, ekonomisi ve dili konusunda bilgi sahibi olmak gerekmektedir. Bu etkenler içerisinde dil yabancı bir ülkede toplumsal etkileşimi ve iletişimi geliştirmek adına önemli bir yer tutmaktadır. İnsanlar, gittikleri ülkenin diline hâkim olduklarında o ülkeye karşı yabancılık hissiyatları azalacak böylece; sosyal, kültürel ve ekonomik anlamda daha etkin olabileceklerdir.

Dil öğrenmenin öneminin artmasına paralel olarak dil öğretimine yönelik hayata geçirilen imkanlar da aynı oranda artmaktadır. Gerek dil öğretiminde gerekse dil öğrenim sürecinde amaca ulaşmak için öğretmen bilgi ve tutumları, kullanılan öğrenme araçları önemli rol oynamaktadır (Akdağ 2007). Yakın geçmişe kadar ağırlıklı olarak dil öğretiminde geleneksel yaklaşımlar olarak nitelendirilen dilin yapısı ve dil bilgisi kurallarına ağırlık veren daha çok ezberlemeyi önceleyen yöntemler kullanılmaktaydı. Dil öğrenimi için bireyler geleneksel yöntemlerin uygulandığ 1 kurslara gitmekte veya özel ders almaktaydı. Geleneksel dil öğretim süreci sistematiğine bakıldığında; öğrenciyi istenen dil düzeyine ulaştırmak için müfredattaki konuların, kolaydan daha karmaşığa, somuttan soyuta doğru birbirini izleyecek şekilde programlandığı ve bunun da dil öğretim sisteminin temelini oluşturan ilkeler olarak karşımıza çıktığı görülmektedir (Demirel, 2003).

Geleneksel dil öğrenimi denince ilk akla gelen ve en çok tercih edilen yerler yabancı dil öğretim kurslarıdır. Bu kurslar ögrencilere; sosyalleşmeye olanak sunması, pratik yapma imkânlarının olması ve rekabetin itici gücünün öğrenmeyi arttırıcı etkisinden faydalanılması gibi avantajlar sunmaktadır. $\mathrm{Bu}$ avantajlarının yanı sıra; uzun zaman gerektirmesi, fiyatlarının fazlalığı, öğrenci sayısının çok olması nedeniyle yaşanabilecek öğrenme güçlüğü ve kaçırılan derslerin telafisinin olmaması gibi etkenler göz önünde bulundurulduğunda dezavantajları da azımsanmayacak orandadır.

Dil öğretim yöntemlerinde amaç öğrenciyi hedefe en hızlı ve güvenli şekilde ulaştırmaktır. Bu noktada, bilişim çağı olarak nitelendirilen günümüzde, öğrenciyi hedefe en hızlı şekilde ulaştırmak adına geleneksel dil öğretim yöntemlerinin yerini teknoloji temelli, modern öğretim yöntemlerinin aldığ görülmektedir. Artık teknoloji, öğrenci yaşamının önemli bir parçası haline gelmiştir. Birçok öğrenci bilgiye erişmek ve bunu kullanmak üzere web tabanlı öğrenmeyi tercih etmektedir (Benson \& Avery, 2009). Bilgisayar ve internet teknolojisi sayesinde dil öğrenmek isteyen bireyler mesafeden bağımsız olarak istedikleri kaynaklara ve kişilere erişebilmektedirler (Yaman \& Bozdemir, 2005).

Dil öğretiminde teknoloji odaklı öğrenme yaklaşımının daha etkin, zevkli, multidisiplinli dolayısıyla daha faydalı olduğuna dair yapılan birçok çalışma bulunmaktadır:

Teknolojinin dil öğrenme eğitimini değiştirdiğine dikkat çeken Arslan, gençlerin teknoloji kullanımına yatkın olmasından dolayı sanal ortamda dil öğrenme üzerine gerçekleştirilen etkinliklerinin her geçen gün arttığını söyleyerek; ilerleyen teknolojik gelişmelerle birlikte dil öğretiminde geleneksel yöntemlerle yapılan işitme, anlama, okuma ve yazma gibi etkinlikler için teknolojinin iyi bir yardımcı olabildiğine vurgu yapmıştır (Arslan, 2009).

Fransızcanın yabancı dil olarak öğretiminde çoklu-ortamlı yazılımlarının yeri ve işlevi üzerine bir çalışma yapan Kartal çalışmasında; çoklu-ortam yazılımlarının iyi bir birikim olduğunu ve zamanla öğretmenin rolünü geliştirip değiştirdiğini belirtmiştir. Bunun yanında bazı eksiklerinin olduğunu ve bunun da zamanla geliştirilebileceğini ifade etmiştir (Kartal, 2005).

Çalışmasında teknolojinin hılı bir şekilde evrim geçirdiğinden bahseden Kessler, teknolojinin öğrenmeyi ve sosyal etkileşime sağladığı katkıdan dolayı öğretmenler tarafından dil öğretiminde her geçen gün daha fazla kullanıldığından bahsetmiştir. Teknoloji, dil öğretiminde kullanılmak istendiğinde çok fazla seçeneğe sahiptir. Arttırılmış gerçeklik, yapay zekâ, büyük veri analitiği, sosyal medya bunlardan bazılarıdır. Bu kavramlar günlük hayatımızın birçok yerinde yaygın olarak kullanılmaktadır (Kessler, 2018).

Yabancı dil öğretiminde sosyal medyanın ve teknolojilik imkanların etkisini inceleyen Taş ve Uğurlu, özellikle akıllı telefon kullanımındaki artışın ortak bir öğrenim amacı ile bir araya gelen grupların sayısının arttırdığına dikkat çekmiştir. Yabancı dil öğretiminde öğrencilerin ilgisini ve motivasyonunu arttırmak için teknolojinin önemli bir etken olduğunu; ayrıca öğrencilere birlikte çalışma yani etkileşim firsatları sunabileceğini belirtmiştir (Taş \& Uğurlu, 2019).

Chilingaryan ve Zvereva çalışmalarında yabancı dil öğretiminde teknoloji temelli eğitimin sağladığ değinmiştir. Yabancı dil öğretiminde teknolojiden faydalanan öğrencilerin diğer öğrencilere göre dile daha çok hâkim oldukları böylece daha başarılı olduklarını ortaya koymuşlardır. Bunun yanında teknolojinin öğrencileri çalışmalarına motive ettiği ve daha başarılı olmalarını sağladığı görülmüştür (Chilingaryan \& Zvereva, 2017).

Çalışmalarında İngilizce öğretiminde teknolojinin önemine ve avantajlarına değinen Shyamlee ve Phil, öğrenmede multimedya kullanımının gerekliliğine vurgu yapmıştır. Teknolojinin uygulamalı öğrenme becerilerini geliştireceğini ve etkileşimli iletişim yeteneğini arttırdığına dikkat çekmiştir (Shyamlee \& Phil, 2012).

Yabanc1 dil öğretiminde bilgi iletişim teknolojilerinin önemine değinen Isisag, küreselleşen dünyada yabancı dil eğitiminin modern araçlara göre kendini yenilemek zorunda olduğunu dile getirmiştir. Bilgi teknolojilerinin eğitime uygun bir şekilde uyarlanması eğitimin kalitesini arttıracak ve daha geniş bir erişim ağı sağlayacaktır. Böylece yaşam boyu öğrenme süreci gelişecektir. Bunun yanında teknoloji odaklı öğrenme öğrencilerin daha hızlı ve başarılı bir öğrenme sağlamalarına olanak sağladığına değinmiştir (Isisag, 2012).

Açıkgöz ve Yalman çalışmalarında teknolojinin özellikle oyunların çocukların öğrenme yetenekleri ve sosyal iletişimleri üzerinde olumlu ve olumsuz etkilerini gösteren bir çalışma gerçekleştirmişlerdir (Yiğit Açıkgöz \& Yalman, 2018).

İngilizce öğretiminde bilişim teknolojileri kullanımını inceleyen Çakıcı, bilişim teknolojileri sayesinde yabancı dil öğrenen öğrencilerin çeşitli iletişim araçları ile etkileşim kurma şansı bulduklarını, böylece üst düzey becerilerini kullanma şansı yakalayarak; eleştirel düşünme yeteneği kazandıklarını ve bilgi 
işleme yeteneklerini kuvvetlendirdiklerini ifade etmişlerdir (Cakici, 2016).

Yabancı dil öğretimi konusunda yapılan çalışmalara ek olarak; bu çalışmada da TÖMER'ler özelinde "Yabancı Dil Olarak Türkçe Öğreniminde geleneksel ve teknoloji temelli yöntemlerin avantaj ve dezavantajları karşılaştırmalı olarak ortaya konmaya çalışılmıştır. Çalışmaya katılan öğrenciler Alanya Alaaddin Keykubat Üniversitesi'nde eğitim alan C1 düzeyi öğrencilerden oluşmaktadır.

\section{Materyal ve Metot}

\subsection{Araştırmanın Amacı ve Veri Toplama Aracı}

Dil öğretiminde izlenecek olan yol, öğrenciyi amacına en hızlı ve en doğru şekilde ulaştıracak en önemli unsurdur. Bu amaçla günümüze kadar dil öğretimine yönelik birçok yöntem geliştirilmiştir. Lakin birçok uygulayıcı ve araştırmacı tarafından hangi yöntem ya da yöntemlerin en uygun olduğu yönünde görüş ayrılıkları bulunmaktadır. Bu çalışmada da Türkçenin yabancı dil olarak öğretiminde geleneksel ve teknoloji temelli öğretim teknikleri kıyaslanmaya çalışılarak, Türkçe öğrenen yabancı öğrenciler için teknoloji yardımı almanın uygunluğu ve geleneksel öğrenmeye göre avantaj ve dezavantajlarını belirlemek amaçlanmıştır. $\mathrm{Bu}$ doğrultuda katılımcıların görüşlerini ayrıntılı bir şekilde ifade etmelerine olanak sağlamak amacıyla Yıldırım ve Şimşek'in (2008) de, nitel araştırmalarda sıklıkla tercih edilen veri toplama aracı olarak nitelendirdiği görüşme tekniği aracılığıyla veriler toplanmıştır.

Araştırma kapsamında, Alanya Alaaddin Keykubat Üniversitesi TÖMER bünyesinde eğitim alan öğrencilerden gönüllük esasına göre 20 kişiyle yarı yapılandırılmış mülakat tekniği uygulanarak görüşmeler yapılmıştır. Görüşmede öncelikle, demografik özellikler ile öğrenme kabiliyet ve tercihleri arasında anlamlı bir ilişki olup olmadığını ölçmek için görüşmecilerin demografik özelliklerine ilişkin bilgiler istenmiştir. Ardından görüşmecilere, okuma becerilerini geliştirmek adına kitap, gazete gibi basılı yayınları mı yoksa teknolojik aygitlar üzerinden okuma yapmayı $\mathrm{m} 1$ daha etkin buldukları, bilgisayar ortamında klavye aracılığı ile mi yoksa manuel yazma becerisini mi tercih ettikleri, dinleme becerisi için yüz yüze diyalog mu yoksa, dijital platformları $\mathrm{m}$ tercih ettikleri, konuşma becerisini geliştirmek için sınıf içi konuşmalarımı yoksa dijital mecralar üzerinden pratik yapmayı $\mathrm{m} 1$ etkin buldukları yönünde sorular yöneltilmiştir.

Görüşmecilerden gelen yanıtlar 1şı̆̆ında 5 ana tema belirlenerek, görüşmecilerin yanıtları literatür doğrultusunda yorumlanmıştır.

\section{Araştırma Sonuçları ve Tartışma}

$\mathrm{Bu}$ bölümde katılımcılar ile yapılan görüşmeler sonucunda elde edilen veriler, temalar halinde ele alınarak ilgili literatür ışı ̆̆ında yorumlanmıştır. Görüşme yapılan kişilerin özellikleri Tablo-1'de, görüşmecilerin verdikleri yanıtlar çerçevesinde oluşturulan temalar ise Tablo-2'te verilmiştir.
Tablo-1 Görüşmecilerin Özellikleri

\begin{tabular}{|c|c|c|}
\hline \multicolumn{2}{|r|}{ Demografik Özellikler } & Sayı \\
\hline \multirow[t]{2}{*}{ Cinsiyet } & Kadın & 7 \\
\hline & Erkek & 13 \\
\hline Yaş & Ortalama & 19 y1l \\
\hline \multirow{3}{*}{ Uyruk } & Afrika & 5 \\
\hline & Orta Asya & 9 \\
\hline & $\begin{array}{l}\text { Rusya Bölgesi } \\
\text { (Ukrayna, Çeçenistan, Gürcistan) }\end{array}$ & 6 \\
\hline
\end{tabular}

Görüşmeye katılanların yaş ortalaması 19'dur. Görüşme yapılan 20 kişinin ülkeleri ise en çok Asya, Rusya ve Afrika bölgesi olmak üzere değişmektedir.

Tablo-2 Görüşme kapsamında oluşturulan temalar

\begin{tabular}{|l|l|}
\hline Tema-1 & TÖMER öncesi Türkçe bilgisi \\
\hline Tema-2 & $\begin{array}{l}\text { Dört temel dil becerisini geliştirmede tercih edilen } \\
\text { yöntem }\end{array}$ \\
\hline Tema-3 & Kullanışlılık acısından tercih edilen yöntem \\
\hline Tema-4 & Tercih edilen teknolojik aygit \\
\hline Tema-5 & Öneriler \\
\hline
\end{tabular}

\begin{tabular}{|l|l|}
\hline Tema-5 & Öneriler \\
\hline
\end{tabular}

Tema 1: TÖMER öncesi Türkçe bilgisi teması altında katılımcılara; TÖMER'de eğitim almadan önce Türkçe bilginiz ne düzeydeydi? Daha öncesinde online ortamda Türkçe öğrenme girişiminiz oldu mu? Olduysa sınıf içi Türkçe öğretimi ile karşılaştırma yapabilir misiniz? Şimdiki eğitiminize ya da Türkiye'de daha rahat iletişim kurmanıza yarayıp yaramadığ konusunda değerlendirir misiniz? gibi sorular yönelmiştir. Katılımcıların sadece 5'i daha önce Türkçe bilgilerinin hiç olmadığını geriye kalanlar ise A1 ve A2 düzeyde Türkçe bilgisine sahip olduklarını belirtmişlerdir. Yine aynı tema altında katılımcıların 6'sı daha önce online ortamlarda hiç Türkçe öğrenme tecrübesinin olmadığını söylerken, geriye kalan katılımcılar ise daha önce online ortamda kendi çabaları ile Türkçe öğrenme deneyimlerinin olduklarını söylemişlerdir. Daha önce online ortamda Türkçe deneyimi yaşayan katılımcılara, bu deneyimlerini geleneksel öğrenme yöntemi olarak tanımlanan TÖMER aracılığı ile aldıkları sınıf içi öğrenme ile kıyaslamaları istenmiştir. Katılımcılar, daha önceki online Türkçe deneyimlerinin sınıf içi çalışmaları kolaylaştırdığını söylerken her iki öğrenme şeklinin kendilerine katkısını ayrı ayrı değerlendirmeleri istendiğinde ise sınıf içi yöntemle dil öğrenmeyi daha verimli bulduklarını söylemişlerdir. A18 olarak kodlanan katılımcı online dil öğrenme şeklinin kedinin tembelleştirdiğini söylerken, A3 olarak kodlanan katılımcı da sınıf içi öğrenmenin motivasyonunu daha yüksek tuttuğunu bu nedenle daha verimli olduğunu dile getirmiştir.

Tema 2: Dört temel dil becerisini geliştirmede tercih edilen yöntem altında katılımcılara; okuma, yazma, dinleme ve konuşma becerilerini geliştirmek için geleneksel yöntem araçlarını mı yoksa teknoloji temelli araçları mı daha etkin ve verimli buldukları yönünde sorular yöneltilmiştir. Katılımcılardan 5'i Türkçe öğrenirken okuma becerisini geliştirmek için; kitap, gazete dergi gibi matbu kaynakları tercih ettiklerini söylerken, 6's1 teknoloji odaklı öğrenmeyi geriye kalanlar ise her ikisini de ortak kullanmayı daha uygun bulduklarını belirtmişlerdir. Aynı tema altında katılımcıların 9'u 
yazma becerilerini geliștirmek için manuel olarak bilinen kâğıt kalem ile yazmayı daha verimli bulduğunu belirtirken, 7'si online ortamda yazmayı tercih ettiklerini, 4 katılımcı ise her ikisinin de kendileri için farkı bulunmadığını belirtmişlerdir. A3 olarak kodlanan katılımcı online yazma şeklini tercih etme sebebini hataların otomatik olarak düzeltilme olanağının olması şeklinde aktarmıştır. Katılımcılardan 10'u dinleme becerisini geliştirmek için yüz yüze yapılan eğitimi daha etkin bulduklarını söylerken, 7'si dijital ortamda dinlemenin daha etkin, 3'ü ise her ikisinin de birbirini tamamladığını söylemiştir. A14 olarak kodlanan katılımcı özellikle yeni başlayanlar için video kayıtların tekrar tekrar dinleme olanağı sunduğu için daha verimli olduğunu belirtmiştir. Türkçe konuşma becerisini geliştirmek için online konuşma yöntemlerimi yoksa sınıf içi yüz yüze konuşma yöntemlerimi sizin için daha verimli oluyor diye sorulan katılımcılardan 18'i sınıf içi yüz yüze konuşmayı daha etkin bulduklarını söylemiş geriye kalan iki katılımcı ise ikisinin de kendileri için önemli bir fark oluşturmadığını söylemiştir.

Tema 3: Kullanışlılık acısından tercih edilen yöntem teması altında katılımcılara; geleneksel öğrenme metotları ile teknoloji odaklı öğrenme yöntemleri kıyaslandığında Türkçe öğrenmede zamanı daha verimli kullanmak ve kullanışlılık olarak hangisini tercih edersiniz? Soruları yönetilmiştir. 10 katılımcı geleneksel yöntemleri, 8 katılımcı teknolojik aygıtların daha kullanışlı bulduğunu söylerken, 2 katılımcı ise her iki yöntemin de yerinin ayrı olduğunu belirtmiştir.

Tema 4: Tercih edilen teknolojik aygit teması altında katılımcılara; teknolojik araçlardan (bilgisayar, tablet ve akıllı telefon vb.) hangisi ya da hangilerinin Türkçe öğrenmek için daha uygun olduğunu düşündüklerini sorulmuştur. Katılımcılardan 8'i büyük ekranda ders çalışmanın daha kolay olduğunu düşündükleri için bilgisayarın kendileri için daha iyi bir öğrenme aracı olduğunu söylerken, 12 katılımcı her yere götürebilme olanağı bulunduğu için telefonun daha kullanışlı olduğunu söylemişlerdir.

Tema: 5: Son olarak öneriler teması altında ise katılımcılara Türkçe öğrenme gayreti ya da istediği içinde olanlara kendi tecrübeleri 1şı̆̆ında herhangi bir önerilerinin olup olmadığ sorulmuştur. Katılımcılar öneri yoğunluğu sırasına göre; pratik yapmayı, Türkçe yayınları izlemeyi, kurslardan eğitim almayı Türkçeyi yeni bir dil olarak öğrenecek kişilere önermişlerdir.

\section{Sonuç}

Jeopolitik özelliklerinden dolayı Türkiye her zaman farklı milletlerin dikkatini çekmiş bir ülkedir. Günümüzde de çeşitli nedenlerle dünyanın dört bir yanından insanlar Türkiye'ye gelmektedir. Özellikle son yıllarda yüksek öğretim alanında yaşanan olumlu gelişmeler eğitim almak için ülkemize gelen öğrencilerin sayısını her geçen gün arttırmaktadır dolayısıyla, yabancılara Türkçe öğretimi konusu da oldukça kritik bir konu olarak karşımıza çıkmaktadır. $\mathrm{Bu}$ noktadan hareketle bu çalışmada, TÖMER bünyesinde Türkçe eğitimi alan öğrencilerin, Türkçe öğrenim süreçlerinde geleneksel öğrenme yöntemlerini mi yoksa, dijital yöntemler aracılığıyla Türkçe öğrenme yöntemlerini mi daha etkin buldukları sorgulanmıştır. Literatür kısmında da belirtildiği üzere, dil öğreniminde teknoloji temelli öğrenmenin önemi üzerine birçok çalışma yer almaktadır. Örneğin; dil öğretiminde teknolojinin entegrasyonu üzerine bir çalışma gerçekleştiren Al-Kadi çalışmasında, öğrenci ve bilişimi öğretimin merkezine alan modellerin geleneksel yaklaşım olan öğretmen ve kitap merkezli modellerin yerine e-ISSN: 2148-2683 geçtiğinden bahsetmiştir. İngilizce öğretiminde bilgisayar ve mobil destekli öğrenme ekseninde gerçekleşen eğitimlerin öneminden ve etkinliklerinden bahsetmiştir (Abdu, 2018). Golonka ve arkadaşları, 350'den fazla çalışmayı gözden geçirdikleri çalışmalarında yabancı dil öğreniminde teknoloji kullanımının etkililiğine dair kanıtları sunmuşlardır. Bahadorfar ve Omidvar çalışmalarında yabancı dil öğreniminde en zorlanılan ve endişe duyulan beceri olan konuşma becerisi konusunda teknolojisinin sağladığı avantajlara değinmiştir. (Bahadorfar \& Omidvar, 2014). Bu çalışmaların aksine Türkçe'nin yabancı dil olarak öğreniminde geleneksel yöntemlerin tercih edildiği görülmektedir.

\section{Kaynakça}

Abdu, A.-K. (2018). A review of technology integration in ELT: From CALL to MALL. Language Teaching and Educational Research, 1(1), 1-12.

Açıkgöz, F.Y., \& Yalman, A. (2018). Dijital oyunların çocukların kişilik ve davranışları üzerinde etkisi: Gta 5 oyunu örneği. Akdeniz Üniversitesi İletişim Fakültesi Dergisi, (29), 163-180.

Arslan, M. (2009). Türkiye'de yabancı dil edinim sorunu ve yabancı dil olarak Türkçe. Paper presented at the 1st International Symposium on Sustainable Development.

Bahadorfar, M., \& Omidvar, R. (2014). Technology in teaching speaking skill. Acme International Journal of Multidisciplinary Research, 2(4), 9-13.

Benson, V., \& Avery, B. (2009). Embedding web 2.0 strategies in learning and teaching. In Web 2.0 (pp. 1-12): Springer.

Cakici, D. (2016). The use of ICT in teaching English as a foreign language. Participatory Educational Research, 4(2), 73-77.

Chilingaryan, K., \& Zvereva, E. (2017). Methodology of flipped classroom as a learning technology in foreign language teaching. Procedia-Social and Behavioral Sciences, 237, 15001504.

Demirel, Ö. (2003). Yabancı dil öğretimi. İstanbul: Pegem Yayıncilik.

Golonka, E. M., Bowles, A. R., Frank, V. M., Richardson, D. L., \& Freynik, S. (2014). Technologies for foreign language learning: A review of technology types and their effectiveness. Computer assisted language learning, 27(1), 70-105.

Isisag, K. U. (2012). The positive effects of integrating ICT in foreign language teaching. Paper presented at the International Conference Proceedings. ICT for Language Learning.

Kartal, E. (2005). Çoklu-ortamlı yazılımların fransızcanın yabancı dil olarak öğretimindeki yeri ve işlevleri. Uludağ Üniversitesi Eğitim Fakültesi Dergisi, 18(2), 231-244.

Kessler, G. (2018). Technology and the future of language teaching. Foreign language annals, 51(1), 205-218.

Shyamlee, S. D., \& Phil, M. (2012). Use of technology in English language teaching and learning: An analysis. Paper presented at the International Conference on Language, Medias and Culture.

Taş, S., \& Uğurlu, M. (2019). Dil eğitiminde teknoloji ve sosyal medya etkisi. In: İstanbul: Gece Akademi.

Yaman, M., \& Bozdemir, O. (2005). Yabanc1 Dil Öğreniminde Teknolojik Yaklaşımlar. Atatürk Üniversitesi Kazım Karabekir Eğitim Fakültesi Dergisi (12), 219-235.

Göçen, G. (2020). Türkçenin yabanc1 dil olarak öğretiminde yöntem. RumeliDE Dil ve Edebiyat Araştırmaları Dergisi, (18), 23-48. DOI: 10.29000/rumelide.705499.

Yıldırım, A. ve Şimşek, H. (2018). Sosyal Bilimlerde Nitel Araştırma Yöntemleri, Seçkin Yayınevi, Ankara 